\title{
Perancangan Enterprise Architecture Universitas Berdasarkan Tri Dharma Perguruan Tinggi Menggunakan Zachman Framework (Studi Kasus: Universitas Komputer Indonesia)
}

\author{
Berny Indrawan \\ Jurusan Magister Sistem Informasi UNIKOM \\ Jl. Dipati Ukur No. 112-116, Bandung, Jawa Barat, Indonesia \\ berny@unikom.ac.id
}

\begin{abstract}
Abstrak - Universitas adalah lembaga yang wajib berkontribusi dalam pendidikan tinggi, penelitian, dan pengabdian kepada masyarakat yang dikenal sebagai Tri Dharma Perguruan Tinggi. Universitas juga memiliki hak untuk mengelola lembaga mereka. Dalam meningkatkan proses bisnis berdasarkan Tri Dharma Perguruan Tinggi, Universitas yang berbasis pada teknologi informasi (IT) harus melakukan perencanaan terhadap blueprint IT untuk mendukung proses penyelarasan antara strategi IT dan strategi bisnis organisasi. Universitas Komputer Indonesia (UNIKOM) sebagai universitas swasta di Kota Bandung, sudah mengimplementasikan infrastruktur IT dan dikelola oleh divisi yang sesuai. Akan tetapi, manajemen IT di UNIKOM yang lebih rumit dan terpisah dari manajemen IT menyebabkan Infrastruktur IT tidak mampu beradaptasi dan menanggapi pesatnya perubahan pada kebutuhan bisnis. Penelitian ini dibangun menggunakan Zachman Framework yang bertujuan untuk merancang Enterprises Architecture agar dapat meningkatkan proses bisnis dan Infrastruktur IT berdasarkan Tri Dharma Perguruan Tinggi di UNIKOM. Namun dalam penelitian ini hanya menggikuti tiga baris pertama pada Zachman Framework yang terdiri dari Planner's View, Owner's View, dan Designer's View serta tiga kolom pertama pada Zachman Framework yang terdiri dari kolom Data (What), Function (How) dan Network (Where). Dengan mengadopsi Enterprise Architecture menggunakan Zachman Framework, dapat menghasilkan blueprint yang dapat dijadikan acuan bagi Universitas untuk melakukan pengambilan keputusan yang lebih baik dan menyelaraskan proses bisnis dan IT di masa mendatang yang sesuai dengan Tri Dharma Perguruan Tinggi.
\end{abstract}

Kata kunci : Tri Dharma Perguruan Tinggi, Enterprise Architecture, Zachman Framework, Blueprint

Abstract-The University is an institution that has mandatory to contribute to higher education, research, and community service as known as Three Pillars of Higher Education. University also has the right to manage their institution. In order to improve their business process based Three Pillars of Higher Education, University-based on Information technology (IT) needs to planning blueprint IT to support the alignment process between IT strategy and organization business strategy. Universitas Komputer Indonesia (UNIKOM) as a private university in Bandung City, already implemented IT infrastructures and managed by appropriate division. However, IT management in UNIKOM more complicated and separate of IT management affects that IT Infrastructure was unable to adapt and response the rapid change of business needs.

This research follows the Zachman Framework to design Enterprises Architecture to improve process business and IT infrastructure based on the Three Pillar of Higher Education in UNIKOM. However, in this research, only follows the first three rows of Zachman Framework, consist of Planner's View, Owner's View and, Designer's View and first three columns of Zachman Framework, consist of Data (What), Function (How) and Network (Where). By adopting Enterprise Architecture using the Zachman Framework, it can produce a blueprint that can be used as a reference for University to make better decisions and alignment of business and IT processes in the future accordance Three Pillar of Higher Education.

Keywords : Three Pillars of Higher Education, Enterprise Architecture, Zachman Framework, Blueprint

\section{Pendahuluan}

Universitas Komputer Indonesia (UNIKOM) sebagai universitas swasta yang berkembang dengan pesat harus mampu bersaing dengan perguruan tinggi lainnya dengan menjalankan proses bisnis yang dapat mendukung peningkatan kualitas pendidikan dan pelayanan terhadap kebutuhan stakeholder UNIKOM. Sebagai universitas berbasis Teknologi Informasi, UNIKOM telah menyediakan layanan infrastruktur IT yang dapat dimanfaatkan oleh civitas akademik untuk menunjang kebutuhan informasi bagi stakeholder UNIKOM. Namun seiring pesatnya pertumbuhan dan perkembangan IT serta proses bisnis di UNIKOM menyebabkan pengelolaan infrastruktur IT di UNIKOM mengalami berbagai kendala dan tidak mampu beradaptasi dan mengikuti perubahan IT dan proses bisnis yang telah dijalankan, sehingga dalam prosesnya penggunaan Infrastruktur IT yang telah berjalan tidak selaras dengan proses bisnis yang dilaksanakan oleh UNIKOM. Oleh karena itu diperlukan perancangan proses bisnis yang selaras dengan penggunaan Infrastruktur IT di UNIKOM.

Berdasarkan peraturan pemerintah Republik Indonesia Nomor 60 tahun 1999 sebuah perguruan tinggi mempunyai tujuan bisnis utama yaitu penyelenggaraan pendidikan/akademik, disamping itu perguruan tinggi juga diwajibkan untuk melakukan kegiatan Penelitian dan Pengabdian pada masyarakat. Selanjutnya peraturan ini juga dikenal dengan Tri Dharma Perguruan Tinggi. Hal ini juga didukung dengan peraturan UU No. 12 Tahun 2012, Pasal 1 Ayat 9 tentang pelaksanaan Tridharma Perguruan Tinggi sebagai kewajiban bagi perguruan tinggi. Berdasarkan aturan aturan tersebut penulis beranggapan bahwa Tri Dharma Perguruan Tinggi dapat dijadikan sebagai indikator keberhasilan sebuah perguruan tinggi. Oleh sebab itu, untuk mendukung upaya peningkatan kualitas pelayanan di 
UNIKOM diperlukan sebuah proses bisnis yang jelas dan mengacu pada Tri Dharma Perguruan Tinggi. Dimana proses bisnis ini juga harus didukung dengan penggunaan infrastruktur IT yang sesuai agar tercipta keselarasan antara proses bisnis dan penggunaan Infrastruktur IT [1] [2].

Dalam penelitian yang dilakukan oleh Heri Santoso meyakini bahwa untuk menunjang kegiatan Tri Dharma Perguruan Tinggi, diperlukan adanya sistem informasi yang baik agar dapat meningkatkan efektifitas dari setiap aktifitas bisnis yang ada. Perencanaan terhadap sistem informasi yang akan dibangun harus sejalan dengan kebutuhan organisasi, serta selaras dengan visi dan misi organisasi, hal ini dapat dilakukan dengan menggunakan perencanaan Enterprise Architecture (EA). Penelitian mengenai perencanaan arsitektur enterprise sistem informasi untuk perguruan tinggi menggunakan metode Zachman Framework (kerangka kerja Zachman) telah dilakukan oleh peneliti sebelumnya, dimana Perancangan EA menggunakan Zachman Framework dapat menghasilkan blueprint yang pada intinya berisi rencana strategis perusahaan dalam mengimplementasikan dan membangun sistem informasi [3] [4] [5].

Mengacu pada penelitian diatas, penulis menganggap bahwa perancangan EA menggunakan Zachman Framework diperlukan untuk menciptakan blueprint yang dapat menghasilkan keselarasan antara Infrastruktur IT dan proses bisnis yang sesuai dengan Tri Dharma Perguruan Tinggi. Dengan terciptanya blueprint diharapkan pencapaian proses bisnis yang dijalankan oleh UNIKOM dapat berjalan sesuai fungsinya, sehingga UNIKOM dapat melakukan pengambilan keputusan dengan mudah saat melaksanakan proses bisnis yang sesuai dengan Tri Dharma Perguruan Tinggi serta dapat meningkatkan kualitas dan memberikan pelayanan terbaik bagi seluruh stakeholder UNIKOM.

\section{Metodologi Penelitian}

Metode penelitian yang digunakan dalam penelitian ini adalah metode Enterprise Architecture Planning (EAP) yang dipetakan kedalam Zachman Framework. EA merupakan pengorganisasian logis untuk proses bisnis dan infrastruktur IT yang berkaitan dengan kebutuhan integrasi dan standarisasi dari sebuah Operating Model perusahaan. Salah satu artefak utama EA adalah model EA, yang memberikan pandangan holistik pada organisasi dan mendukung pemangku kepentingan EA untuk menciptakan nilai tambah [6]. Dalam penelitian [7] menyatakan bahwa metodologi EAP berfungsi sebagai dasar bagi banyak metodologi EA modern. Metode EAP yang akan digunakan dalam penelitian ini memiliki empat tahapan alur yaitu: 1) Inisiasi Perencanaan, 2) Pemodelan bisnis, analisis sistem dan teknologi yang sedang berjalan, 3) Analisis arsitektur data, arsitektur aplikasi, dan arsitektur teknologi. 4) Rencana Implementasi/Migrasi. Empat tahapan alur metode EAP dapat dilihat pada gambar 1 berikut ini:

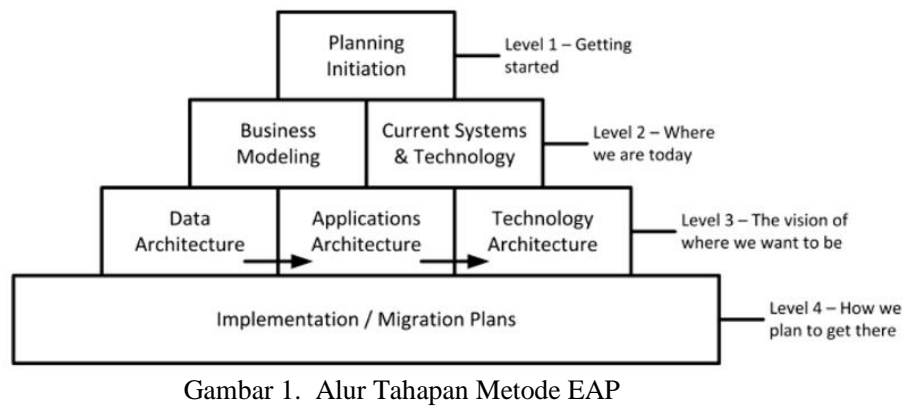

Zachman Framework merupakan skema untuk melakukan klarifikasi pengorganisasian artifak enterprise [8]. Zachman Framework didesain untuk memasukkan representasi arsitektur sistem informasi untuk semua pihak yang terlibat dalam kegiatan pengembangan, pengelolaan, perawatan, dan penggunaan dari sistem informasi suatu organisasi. Setiap perspektif memberikan cara pandang yang unik dan bernilai pada arsitektur enterprise [9]. Menurut [10] Zachman Framework menggambarkan arsitektur organisasi secara umum dan menguraikannya sebagai enterprise system yang kompleks. Dalam dunia bisnis, organisasi dituntut melakukan manajemen perubahan. Tujuan dari manajemen perubahan berhubungan dengan keunggulan bersaing antara organisasi dengan para pesaingnya. Dalam penelitian ini penulis hanya akan melakukan penelitian hingga 3 tahapan baris analisis Zachman Framework, adapun 3 tahapan baris ini meliputi: Scope (Planner's View), Business Model (Owner's View), System Model (Designer's View) dengan kolom Data (What), Function (How) dan Network (Where). Hubungan antara Zachman Framework dan EAP adalah proses mendefinisikan dua level atas Zachman Framework, sehingga jika dipetakan ke dalam Zachman Framework, EAP akan berada dibaris pertama dan baris kedua yang merupakan perspektif perencana dan pemilik. Aspek yang dibahas dalam EAP berada pada tiga kolom dari Zachman Framework, yaitu meliputi data, fungsi dan jaringan dari arsitektur sistem informasi [4] [11]. Hubungan Zachman Framework dan EAP dapat dilihat pada Gambaran tahapan Zachman Framework berikut ini [12]:

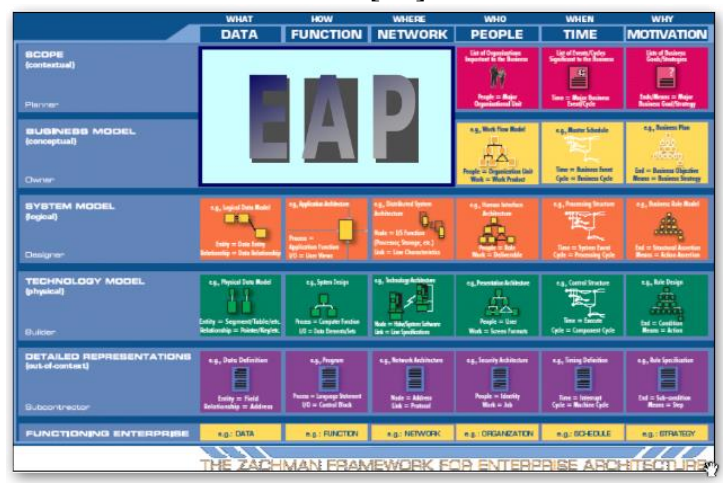

Gambar 2. Model Zachman Framework

Data pendukung yang digunakan dalam penelitian ini berdasarkan dari data Executive Information System (EIS) UNIKOM. 


\subsection{Kerangka Kerja Penelitian}

Tahapan yang dilakukan selama penelitian ditunjukkan pada gambar 3 berikut ini :

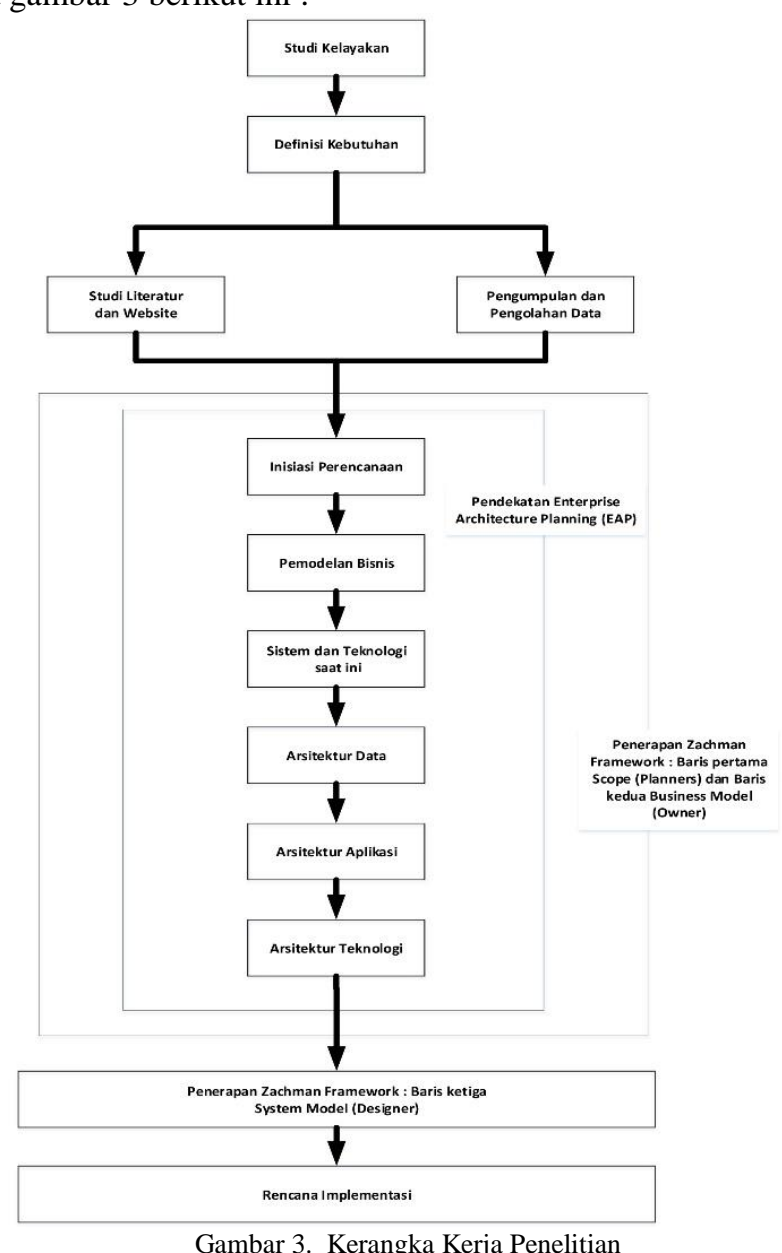

\subsection{Model Rantai Nilai (Value Chain)}

Dalam penelitian ini digunakan model rantai nilai (Value Chain) sebagai metode analisis. Value Chain menurut [13] diperkenalkan oleh Porter (1985) yang terdiri dari satu rangkaian aktivitas yang menciptakan dan membangun suatu nilai yang dapat menghasilkan margin nilai tambah bagi organisasi. Penelitian yang dilakukan oleh Michael Porter, menghasilkan sebuah konsep bernama Konsep porter's valueadded chain [14], konsep ini bertujuan untuk membagi fungsifungsi utama di organisasi ke dalam dua kelompok besar, yaitu aktivitas utama (primary activities) dan aktivitas pendukung (support activities).

Identifikasi aktivitas utama dan pendukung UNIKOM dapat ditunjukkan dengan menggunakan rantai nilai dapat dilihat pada gambar 4 .

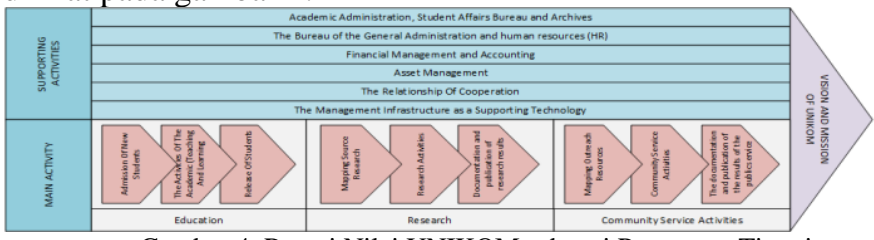

Gambar 4. Rantai Nilai UNIKOM sebagai Perguruan Tinggi

\section{HASIL DAN PEMBAHASAN}

Penerapan Zachman Framework dalam penelitian ini dapat dilihat berdasarkan tahapan yang dilakukan dalam mendefinisikan dan membuat blueprint yang menghasilkan keselarasan antara infrastruktur IT dan proses bisnis organisasi yang sesuai dengan Tri Dharma Perguruan Tinggi. Adapun tahapan yang harus dilakukan yaitu mendefinisikan lapisan 1 (posisi awal mulai), lapisan 2 (posisi saat ini) dan lapisan 3 (posisi yang diinginkan dimasa mendatang) dengan perspektif baris pada Zachman Framework yang digunakan dalam penelitian ini hanya Perspektif Perencana (Planner), Perspektif Pemilik (Owner), Perspektif Perancang (Designer) dengan bahasan kolom Data, Function dan Network.

\subsection{Lapisan I (Posisi Awal Mulai)}

Pada tahapan ini hal yang pertama dilakukan yaitu melakukan inisiasi perencanaan yang berfungsi untuk mempersiapkan pelaksanaan EA. Tahapan ini menjadi point utama yang dianggap penting karena tahapan ini dapat menentukan langkah pengerjaan apa saja yang harus dilakukan peneliti dalam menentukan proses tahapan yang harus dikerjakan selanjutnya. Adapun hasil keluaran yang dapat dihasilkan dari tahapan ini adalah:

1. Dapat mendefinisikan ruang lingkup perancangan EA dengan menjadikan Tri Dharma Perguruan Tinggi sebagai Scope dari penelitian ini.

2. Sasaran dari perancangan EA yaitu menciptakan blueprint IT dengan Scope Tri Dharma Perguruan Tinggi.

Sesuai dengan keberadaan UNIKOM sebagai perguruan tinggi maka Indikator keberhasilan dari visi dan misi yang telah dibuat oleh UNIKOM dapat dilihat dari keberhasilan dalam menjalankan Tri Dharma Perguruan Tinggi oleh karena itu keputusan dan penentuan strategi bisnis yang harus dijalankan oleh UNIKOM harus mengacu pada Visi, Misi dan Tri Dharma Perguruan Tinggi.

\subsection{Lapisan II (Posisi Saat Ini)}

Tahapan dalam lapisan ini bertujuan untuk memberikan gambaran dari kondisi enterprise saat ini, dimana kegiatan yang dilakukan dalam tahapan ini meliputi: Pemodelan Bisnis serta Sistem dan teknologi saat ini.

Dalam penelitian ini, Permodelan bisnis yang akan diterapkan harus mengacu pada Tri Dharma perguruan tinggi, sehingga aktivitas utama yang harus dijalankan oleh UNIKOM yaitu Pendidikan, Penelitian dan Pengabdian Masyarakat dengan aktivitas pendukung yaitu Penunjang Tri Dharma. Pemodelan bisnis yang akan diterapkan digambarkan menggunakan Value Chain yang dapat dilihat pada gambar 5.

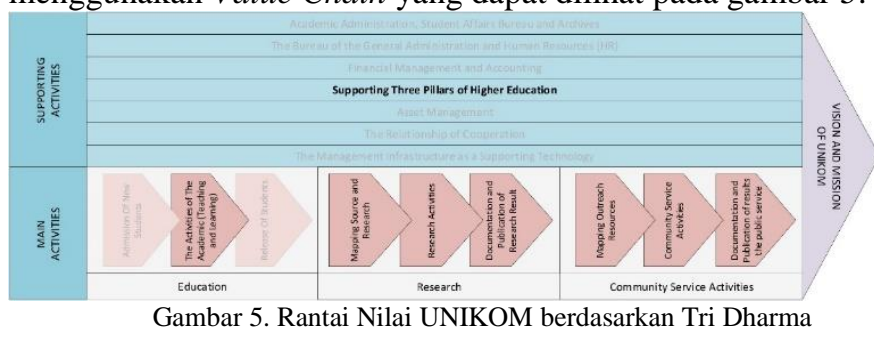


Sedangkan tujuan dari tahapan sistem dan teknologi saat ini dilakukan untuk mendapatkan gambaran sistem dan teknologi yang berjalan dalam bentuk Information Resouces Catalog (IRC) yang didapat dengan menentukan hubungan antara aplikasi dan teknologi dengan fungsi bisnis yang sedang berjalan saat ini. Tahapan ini bertujuan untuk mengetahui fungsi bisnis mana saja yang telah didukung aplikasi dan teknologi serta sistem apa saja yang telah didukung oleh teknologi.

\subsection{Bagan Hierarki Fungsi Utama UNIKOM}

Bagan hierarki fungsi utama UNIKOM berfokus pada aktivitas utama berdasarkan Tri Dharma dan aktivitas pendukung Tri Dharma yang dapat dilihat pada gambar 6 .

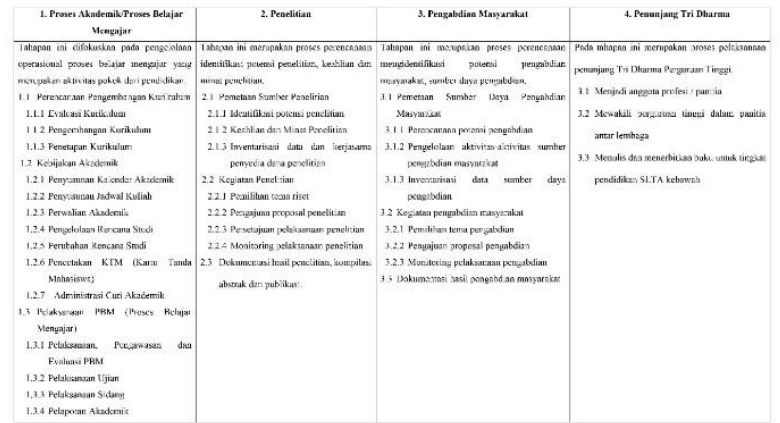

Gambar 6. Hierarki Fungsi Utama UNIKOM berdasarkan Tri Dharma

\subsection{Lapisan III (Posisi yang Diinginkan Dimasa Mendatang)}

Lapisan ini menggambarkan posisi sistem yang diinginkan dimasa yang akan datang. Dimana penggambarannya dituangkan kedalam bentuk arsitektur data, aplikasi dan teknologi.

\subsubsection{Arsitektur Data}

Tujuan dari tahapan ini untuk mendefinisikan semua entitas data yang dianggap penting dalam mendukung fungsi binis yang telah didapat dari tahap sebelumnya, yaitu pada lapisan II tahap permodelan bisnis. Pada tahapan ini data akan digunakan untuk membangun arsitektur aplikasi yang sesuai dengan Tri Dharma perguruan tinggi.

Sesuai dengan kondisi rantai nilai yang didapat dari tahapan sebelumnya, maka diperoleh kandidat entitas data yang didapat dari entitas bisnis yang dapat dilihat pada gambar 7 .

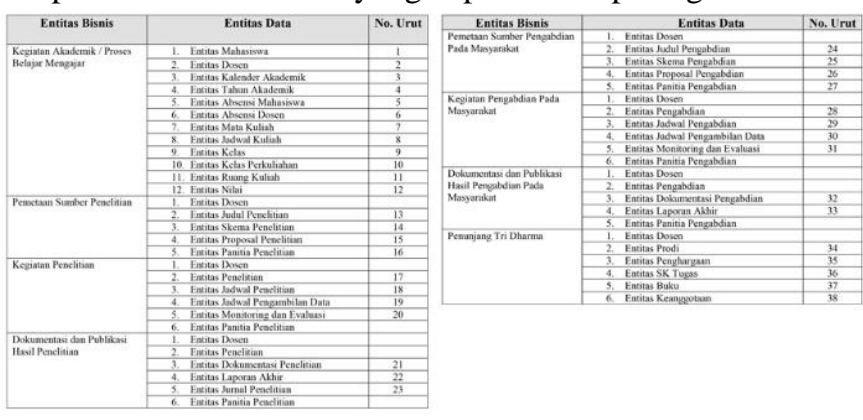

Gambar 7. Entitas Data UNIKOM

\subsubsection{Entitas Set, Atribut dan Relasinya}

Untuk menggambarkan hubungan antar entitas, maka penggambaran konseptual relasinya dapat digambarkan dengan menggunakan Entity Relationship Diagram (ERD). Gambar hasil relasi antar entitas dapat dilihat pada tampilan gambar 8 .
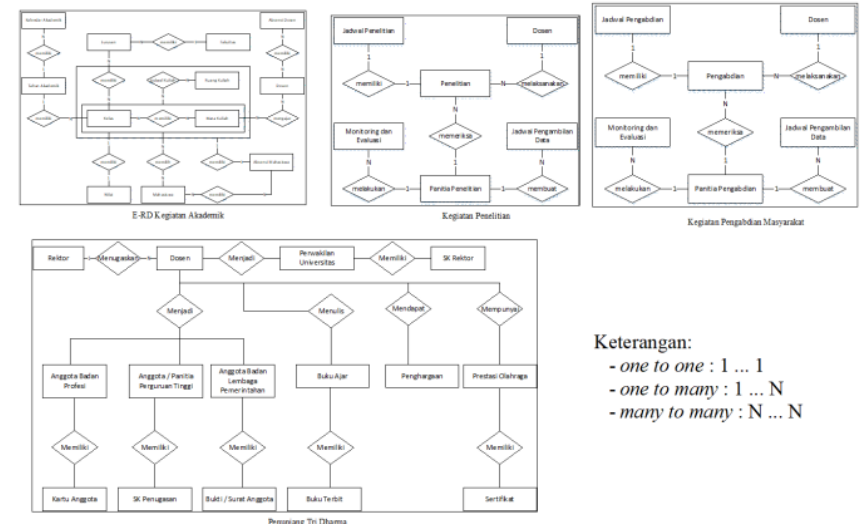

Keterangan

one to one : $1 \ldots 1$ one to many: $1 \ldots \mathrm{N}$

Gambar 8. ERD Tri Dharma Perguruan Tinggi

\subsubsection{Arsitektur Aplikasi}

Pada tahapan ini kandidat aplikasi didefinisikan dengan membuat daftar kandidat aplikasi berdasarkan matriks hubungan fungsi bisnis dan entitas data yang akan mendukung aktivitas utama dan aktivitas pendukung berdasarkan Tri Dharma perguruan tinggi. Pendefinisian aplikasi berdasarkan dekomposisisi fungsi bisnis yang telah dilakukan sebelumnya, hal ini diperlukan dalam mendukung fungsi bisnis Enterprise dan pengelolaan data [15] yang dapat dilihat pada gambar 9 .

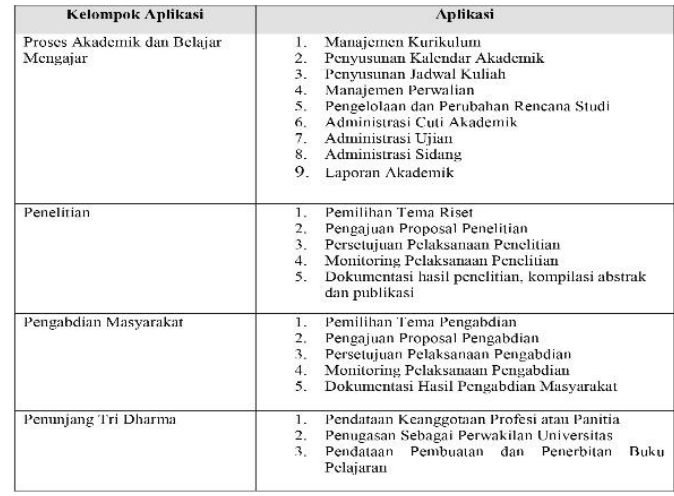

Gambar 9. Daftar kandidat Aplikasi

\subsubsection{Arsitektur Teknologi}

Analisis terhadap arsitektur teknologi dilakukan untuk mendefinisikan kebutuhan teknologi dalam melakukan pengolahan data. Hasil akhir dari analisis ini bertujuan untuk menghasilkan pemilihan teknologi yang dibutuhkan oleh aplikasi, mulai dari perangkat lunak, system operasi, teknologi keamanan, arsitektur jaringan dan internet yang berfungsi untuk mendukung jalannya aplikasi. Analisis ini dilakukan dengan melihat teknologi yang berjalan saat ini dengan teknologi yang akan diperlukan di masa depan dalam menunjang stategi bisnis dari organisasi sehingga dapat menempatkan infrastruktur teknologi baru yang akan dibutuhkan untuk dapat diimplementasikan di kemudian hari [7]. 

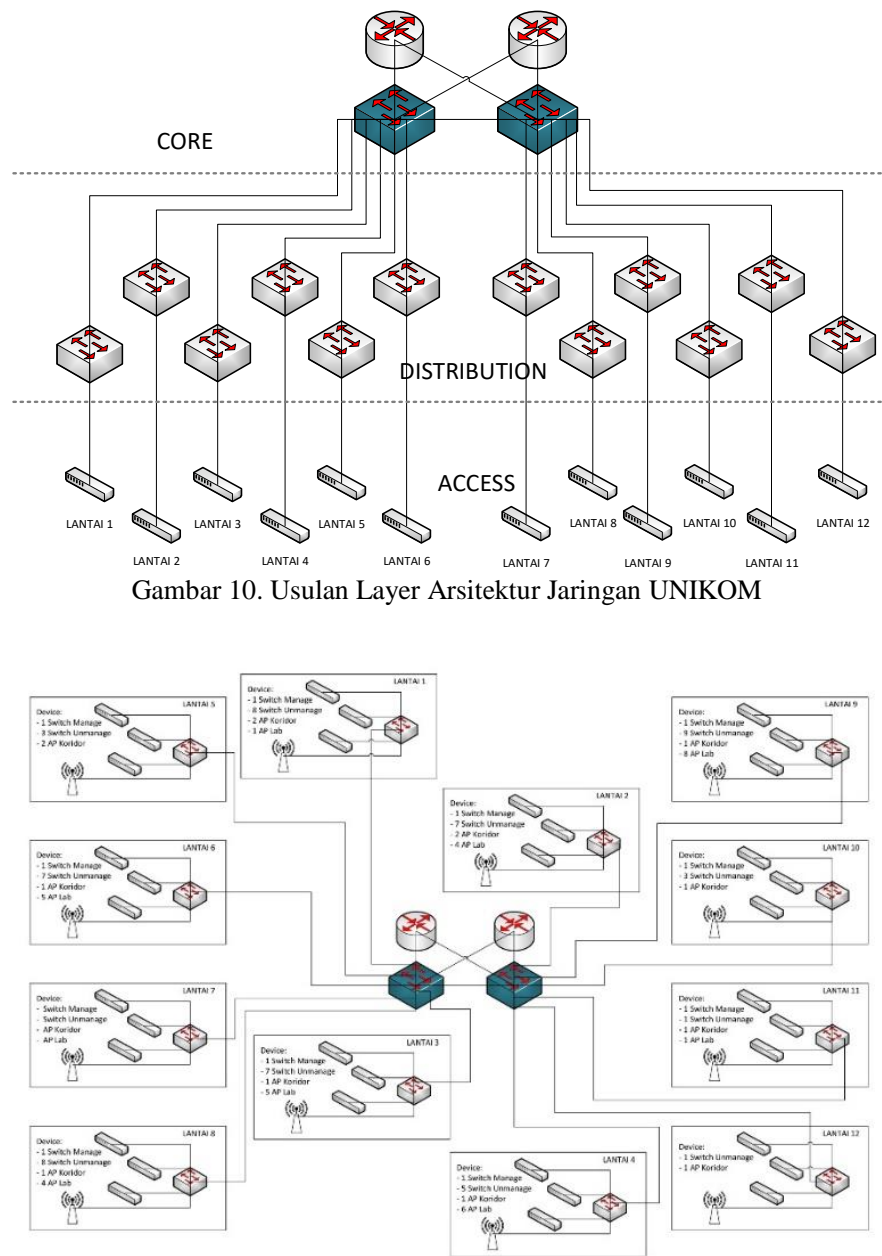

Gambar 11. Usulan Konsep Arsitektur Teknologi

Arsitektur jaringan yang digambarkan diatas merubah desain jaringan yang lama dengan menambahkan:

1. Menambahkan Firewall pada core network UNIKOM untuk mendukung keamanan arsitektur aplikasi yang berbasis online.

2. Menambahkan link backup untuk menghindari down time dari aplikasi yang dikembangkan.

3. Memperbaiki kualitas layanan dalam mengakses sistem informasi dengan memisahkan akses aplikasi internet dan jaringan local.

4. Menambahkan infrastruktur jaringan wireless untuk memberikan kemudahkan akses aplikasi yang dikembangkan melalui perangkat mobile.

5. Mendukung pola pengembangan aplikasi berbasis web.

\subsection{Rencana Implementasi/Migrasi}

Manfaat yang didapat dari perencanaan implementasi adalah untuk mempersiapkan strategi yang diperlukan dalam proses implementasi arsitektur-arsitektur yang dirancang pada tahapan sebelumnya. Rencana implementasi merupakan langkah terakhir yang harus ditempuh dalam merancang EA. Pengurutan rencana implementasi juga penting untuk dilakukan, hal ini dapat dilakukan dengan mempertimbangkan pengelompokan aplikasi berdasarkan fungsi bisnis yang telah ditetapkan.

\subsection{Urutan Implementasi Aplikasi}

Urutan implementasi aplikasi dilakukan untuk mendapatkan gambaran hubungan antara entitas data dengan aplikasi yang diperoleh dari hasil matriks antara entitas data dengan aplikasi, begitu juga dengan matriks antara aplikasi dengan fungsi bisnis bertujuan untuk memudahkan dalam mendefinikan alur data sharing dalam arsitektur aplikasi dan untuk digunakan sebagai acuan dalam membangun aplikasi sesuai dengan urutan aplikasi yang menghasilkan data, memiliki prioritas terlebih dahulu dari pada aplikasi yang menggunakan/membutuhkan data.

Pengurutan implementasi aplikasi diperlukan untuk menentukan prioritas aplikasi yang akan dikembangkan sesuai dengan arsitektur yang telah dibuat. Dengan melakukan pengurutan tersebut maka penerapan implementasi aplikasi menggunakan EA dapat diterapkan dengan baik. Adapun gambaran urutan Implementasi aplikasi dapat dilihat pada gambar 12.

\begin{tabular}{|c|l|c|}
\hline NO & \multicolumn{1}{|c|}{ APLIKASI } & KETERANGAN \\
\hline 1 & Pemilihan Tema Riset & Pengembangan Baru \\
\hline 2 & Pengajuan Proposal Penelitian & Pengembangan Baru \\
\hline 3 & Persetujuan Pelaksanaan Penelitian & Pengembangan Baru \\
\hline 4 & Monitoring Pelaksanaan Penelitian & Pengembangan Baru \\
\hline 5 & Pemilihan Tema Pengabdian & Pengembangan Baru \\
\hline 6 & Pengajuan Proposal Pengabdian & Pengembangan Baru \\
\hline 7 & Persetujuan Pelaksanaan Pengabdian & Pengembangan Baru \\
\hline 8 & Monitoring Pelaksanaan Pengabdian & Pengembangan Baru \\
\hline 9 & Pendataan Keanggotaan Profesi atau Panitia & Pengembangan Baru \\
\hline 10 & Penugasan Sebagai Perwakilan Universitas & Pengembangan Baru \\
\hline 11 & Pendataan Pembuatan dan Penerbitan Buku Pelajaran & Pengembangan Baru \\
\hline
\end{tabular}

Gambar 12. Urutan Implementasi Aplikasi

\section{KESIMPULAN}

Berdasarkan hasil dari tahapan penelitian sebelumnya, maka didapatkan kesimpulan sebagai berikut ini:

1. Perancangan EA dengan menggunakan metode analisis Zachman Framework telah berhasil dibuat dan menghasilkan blueprint yang berisi pemodelan terhadap arsitektur data, aplikasi dan teknologi yang dapat dijadikan landasan perbaikan dan pengembangan sistem informasi di Universitas Komputer Indonesia (UNIKOM) dalam meningkatkan kualitas layanan kepada seluruh stakeholder UNIKOM.

2. Blueprint yang dihasilkan telah berhasil menyelaraskan Infrastruktur IT dengan proses bisnis yang sesuai dengan Tri Dharma Perguruan Tinggi.

3. Perancangan blueprint menghasilkan gambaran sistem informasi dan teknologi pendukung yang dibutuhkan pada kondisi saat ini maupun pada kondisi mendatang.

4. Perancangan EA diperlukan agar setiap organisasi memiliki pedoman pengembangan sistem informasi yang dapat dimanfaatkan bagi organisasi maupun perusahaan.

5. Perancangan EA dapat memberikan acuan investasi teknologi jangka panjang dengan mempertimbangkan 
kepentingan dan fungsi bisnis yang dijalankan oleh UNIKOM

6. Penggunaan Zachman Framework pada perancangan EA memberikan kemudahan bagi penguna dalam menentukan setiap tahapan atau langkah pengerjaan yang harus dibuat dalam menyusun perancangan EA.

7. Berdasarkan hasil temuan dan observasi yang telah dilakukan dalam penelitian ini, terjadi beberapa redudansi atau pengulangan data mahasiswa yang menyebabkan penginputan dan pengelolaan data menjadi tidak efisien. Oleh karena itu, perancangan EA diperlukan untuk memaksimalkan penggunaan Infrastruktur IT dan proses bisnis agar dapat membangun arsitektur aplikasi yang dapat mengautomatisasi data sehingga diharapkan dapat meminimalisir redudansi data yang kerap terjadi.

8. Sistem aplikasi yang tersedia saat ini di UNIKOM hanya berfokus pada fungsi operasional akademik saja.

9. Ditemukan beberapa aplikasi dan sistem informasi yang memiliki kesamaan fungsional, hal ini terjadi dikarenakan tidak ada kejelasan aturan atau kebijakan yang diterapkan di UNIKOM, sehingga dengan adanya perancangan EA pada penelitian ini diharapkan dapat membantu UNIKOM dalam pengambilan keputusan untuk membuat dan menentukan arah aturan atau kebijakan (policy)

10. Pemanfaatan penggunaan Executive Information System (EIS) di UNIKOM belum dilakukan secara optimal, sehingga stakeholder UNIKOM mengalami beberapa kesulitan dalam memperoleh informasi secara utuh.

\section{UCAPAN TERIMA KASIH}

Penulis mengucapkan terima kasih Kepada Bapak Assoc. Prof. Dr. Ir. Eddy Soeryanto Soegoto, MT. selaku Rektor dan Pimpinan Universitas Komputer Indonesia (UNIKOM) yang telah memberikan banyak support dan dorongan baik moril dan materil kepada penulis untuk menyelesaikan penelitian ini. Ucapan terima kasih juga disampaikan kepada Bapak Dr. Yeffry Handoko Putra, ST., M.T selaku Ketua Program Studi dan Dosen Magister Sistem Informasi UNIKOM. Terima kasih secara khusus dikirimkan kepada Bapak Irfan Dwiguna Sumitra, M.Kom., Ph.D selaku Dosen Pembimbing yang telah banyak memberikan masukan, arahan dan bimbingan serta semangat kepada penulis untuk menyelesaikan penelitian ini, serta kepada seluruh pihak yang membantu kelancaran penelitian ini.

\section{REFERENSI}

[1] Peraturan pemerintah Republik Indonesia, "Nomor 60 tahun," 1999

[2] R. Indonesia, "Undang - Undang Republik Indonesia, Nomor 12 Pasal 1 Ayat 9 Tahun 2012 tentang Pendidikan Tinggi," Sekretariat Negara, Jakarta, 2012.

[3] A. P. Utomo, "Pemodelan Arsitektur Enterprise Sistem Informasi Akademik pada Perguruan Tinggi menggunakan Enterprise Architecture Planning," Jurnal SIMETRIS ISSN: 2252- 4983, vol. 5 No.1, 2014.

[4] H. Santoso, "Perencanaan Arsitektur Enterpise Sistem Informasi Untuk Perguruan Tinggi Dengan Zachman Framework.," RESEARCH: Computer, Information System \& Technology Management 1.02, pp. 3238, 2018.

[5] B. w. Suharjito, "Pengembangan Blueprint IT dengan Zachman Framework di STP Trisakti," Journal of Information System, vol. 13, nr 1, 2017.

[6] S. H. Horst Lichter, "A Probabilistic Enterprise Architecture Model Evolution," IEEE 22nd International Enterprise Distributed Object Computing Conference (EDOC). , pp. 51-57, 2018.

[7] S. Kotusev, "The History of Enterprise Architecture: An EvidenceBased Review," Journal of Enterprise Architecture, Vol. \%1 av \%212, No. 1 , 2016

[8] R. I. Johanes, "Perancangan Enterprise Architecture Menggunakan Zachman Framework (Studi Kasus: PT. Vivamas Adipratama),' Seminar Nasional Sains dan Teknologi ISSN 2460 - 8416, 2017.

[9] H. H. Solihin, "Perancangan Enterprise Architecture untuk Penerapan Manajemen Inovasi menggunakan Zachman Framework pada Pusat Penelitian Tenaga Listrik dan Mekatronik Lembaga Ilmu Pengetahuan Indonesia," i Seminar Nasional dan Tren (SNIT), 2015

[10] F. A. Husni, ”Analisis Dan Pengembangan Sistem Informasi Akademik Dengan Permodelan Enterprise Architecture Zachman Framework Pada Politeknik Jambi," Jurnal INFORMA Politeknik Indonusa Surakarta ISSN: 2442-7942, vol. 1 Nomor 3, 2016.

[11] H. Muhammmad, "Penyusunan Rencana Strategis SIstem Informasi STKIP PGRI Banjarmasin Menggunakan Enterprise Architecture Planning," Jurnal Teknologi Rekayasa, vol. 2 No. 2, pp. 63-72, 2017.

[12] H. Kurniawan, "Penggunaan Enterprise Architecture Planning dalam Pemodelan Bisnis Pendidikan dan Pelatihan," Jurnal Tim Darmajaya, vol. 1 No. 02, 2015.

[13] L. J. Christine Legner, "Overcoming implementation challenges in enterprise architecture management: a design theory for architecturedriven IT Management (ADRIMA)," Information Systems and $e$ Business Management 12.1 , pp. 101-137, 2014.

[14] A. P. G. Danny Greefhorst, "A framework for analysis and design of software reference architectures.," Information and Software Technology 54.4, pp. 417- 431, 2012.

[15] J. C. W. Yeffry Handoko, ”Perancangan Arsitektur Enterprise di Balai Lalu Lintas Angkutan Jalan Sungai Danau dan Penyebrangan Menggunakan EAP," Jurnal Tata Kelola dan Kerangka Kerja Teknologi Informasi 2460-1799, vol. 1, 2015. 